\title{
Long-term Deflection of Timber- Concrete Composite Beams in Cyclic Humidity Conditions in Bending
}

\author{
M. Hailu ${ }^{1}$, R. Shrestha ${ }^{2}$, K. Crews ${ }^{3}$
}

${ }^{1}$ Center for Built Infrastructure Research, Faculty of Engineering and IT, University of Technology, Sydney, P. O. Box 123 Broadway 2009, NSW Australia; email: Mulugheta.Hailu@uts.edu.au.

${ }^{2}$ Lecturer, Centre for Built Infrastructure Research, Faculty of Engineering and IT, University of Technology, Sydney, P. O. Box 123 Broadway 2009, NSW Australia; e mail: Rijun.Shrestha-1@eng.uts.edu.au.

${ }^{3}$ Professor of Structural Engineering, Centre for Built Infrastructure Research, Faculty of Engineering and IT, University of Technology, Sydney, P. O. Box 123 Broadway 2009, NSW Australia; e mail: keith.Crews@uts.edu.au.

\begin{abstract}
A laboratory investigation to determine the long-term behaviour of TimberConcrete Composite (TCC) beams was started from August 2010 at the University of Technology, Sydney. The test was conducted on four six-meter-span TCC beams; this paper reports the results to-date for only two beams. The materials used are laminated veneer lumber (LVL) for the joists and $32 \mathrm{MPa}$ concrete for the flanges. From the start of the test (August 2010), the specimens have been under sustained loads of $(1.7 \mathrm{kPa})$ whilst the environmental conditions have been cyclically alternated between normal and very humid conditions (typical cycle duration is six to eight weeks) and the temperature remains quasi constant $\left(22^{\circ} \mathrm{C}\right)$. During the test, the midspan deflection, moisture content of the timber beams and relative humidity of the air are continuously monitored. The investigation is still continuing and this paper reports the results of the experimental investigation for the last two and half years.
\end{abstract}

\section{INTRODUCTION}

Timber-concrete composite (TCC) floor system is a construction technique where by the concrete is placed on top of the timber joist and connected with shear connectors such that timber and concrete work as a composite element and are essentially in tension and compression, respectively. The three components of TCC floors; timber, concrete and connection, are characterized by different time dependent behaviour. This behaviour is affected by, the stress level, moisture content, temperature and relative humidity of air. Concrete is characterized by significant creep and shrinkage phenomena, timber by creep, mechano-sorptive and shrinkage/swelling (Ahmadi 1993, Armstrong 1960, 1961 \& 1972, Brebbia 1991, Toratti 1993, Bou Said 2004, Ceccotti 2006, Epmeier 2007), and connection by creep and mechano-soptive effect. Due to complexity of the composite action, a series of experimental tests is desirable in order to investigate the behaviour of the composite 
structures. There are hardly available literatures on long-term deflection of TCC beams under cyclic humidity conditions but a few long-term tests performed on TCC structures so far are reported in (Ahmadi 1993, Brebbia 1991, Bou Said 2004, Ceccotti 2006, Fragiacomo 2007, Grantham 2004, Hailu 2012, Meierhofer 1993).

Yeoh (2010) tested three 8 meters T-section TCC floor beams with three types of connectors in uncontrolled, unheated indoor environment, classified as service class 3 as per Euro code 5. The test result showed largest creep coefficients for plate connection and least with rectangular notch connection. The long-term deflection for beams with normal concrete was larger than the beams with low shrinkage concrete.

Ceccotti (2006) tested a $6 \mathrm{~m}$ span TCC floor system with glue in connection in outdoor unsheltered well ventilated conditions and protected from direct radiation from the sun. The test lasted for five years and it was classified as service class 3 as per Euro code 5.The maximum average deflection monitored throughout the test was $3.36 \mathrm{~mm}$, which was almost four times the instantaneous elastic deflection and is well below the limiting value L/300 as per the Euro code 5 (2008).

Bou Said (2004) monitored a composite beam with glue-in mechanical connectors loaded in sheltered outdoor conditions for 2 years. The short term deflection estimated using Euro code 5 was exceeded and it also exceeded the long-term deflection limits.

Grantham et al. (2004) reported results on a full-scale long-term test performed on a timber floor strengthened with SFS screws and lightweight aggregate concrete.

Meierhofer (1998) conducted a long-term bending test on a $4 \mathrm{~m}$ span beam with SFS screw connectors under relatively unfavourable conditions: outside under roof, i.e. the specimens were fully exposed to the natural temperature changes and wetting cycles which provide to be a very dominating influence. The creep factor after one year varied between 2 and 4 .

Ahmadi (1993) tested a simply supported $3.9 \mathrm{~m}$ long TCC slab loaded with a full sustained live load of $2 \mathrm{kN} / \mathrm{m}^{2}$ for 140 days. The ultimate long-term deflection under this $100 \%$ sustained live load was within acceptable limits set by the building codes AITC and ACI 318-89 and the relative dimensional changes in the timber joists due to variations of humidity and temperature caused cracks in the concrete.

Brebbia et al. (1991) conducted long-term experimental investigation on a $4 \mathrm{~m}$ span TCC beam with gang-nail connector type for about two years and the final deflection was about 4 times that of the no-slip theory and about 2.5 times the actual value under short term load.

The present research work aims to obtain detailed experimental result about the longterm deflection of the composite beams subjected to sustained loads for about two and half years. Particular attention is devoted to behaviour of the beams in cyclic humidity conditions. 


\section{EXPERIMENTAL PROGRAM}

Two TCC beams with identical geometry, each with a clear span of $5.8 \mathrm{~m}$, are currently being tested under long-term test in the civil engineering structures laboratory at University of Technology Sydney which was started on 04-August2010, 200 days after the concrete pour.

\subsection{CHARACTERISTICS OF THE COMPOSITE BEAMS}

The top slab is made of a normal weight concrete with commercial strength of $32 \mathrm{MPa}$, the test results for the concrete compressive strength after 28, 56 and 91 days were $39.5,44.3$ and $50.3 \mathrm{MPa}$, respectively. The mean drying shrinkage was 800 micro strains at 28 days. A standard reinforcing mesh of $7 \mathrm{~mm}$ diameter normal strength reinforcement bars at $200 \mathrm{~mm}$ spacing was provided in the concrete slab to prevent shrinkage cracks. Figure 1, shows typical cross-section of the beams under investigation.

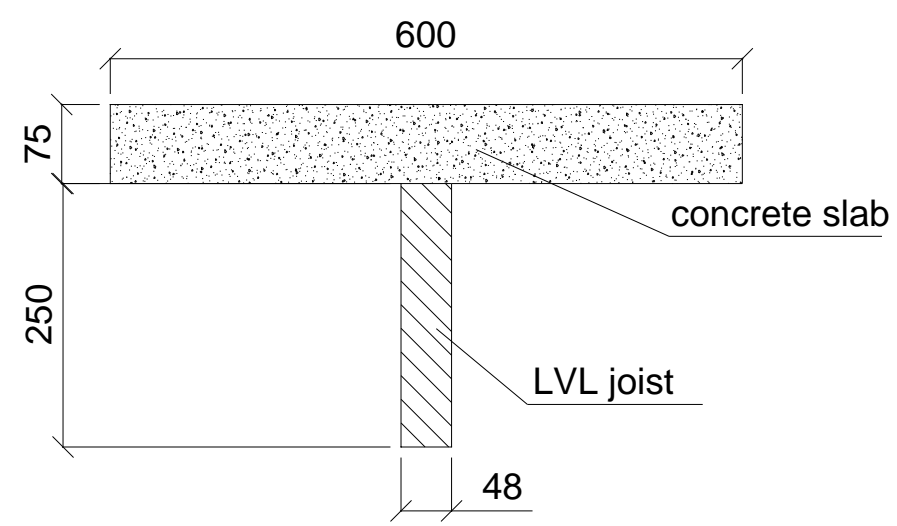

Figure 1. Cross-section of the TCC beam (Typical) (measured in mm).

The joists are made of $250 \times 48 \mathrm{~mm}$ laminated veneer lumber (LVL). The mean modulus of elasticity and characteristic bending strength of the LVL was $12.3 \mathrm{GPa}$ and $48 \mathrm{MPa}$, respectively. Two types of shear connector configurations were used in the beams. The first beam, B_6N, had six bird's-mouth notch connections ( Figure 2). The second beam, referred to as B_SFS, was constructed with a pair of SFS screws at $\pm 45^{\circ}$ angles ( Figure 2) and with a spacing of $300 \mathrm{~mm}$ between pairs of screws. Series of push-out tests were conducted (Khorsandnia et al. 2012) to determine the slip modulus of the connectors and the results are tabulated below in Table 1. Layout of the connectors along the span of each of the tested beams is shown in Figure 3.

Table 1. Type of connector and slip modulus.

\begin{tabular}{llll} 
Specimen & Type of connector & Slip modulus, & Characteristic \\
\hline
\end{tabular}




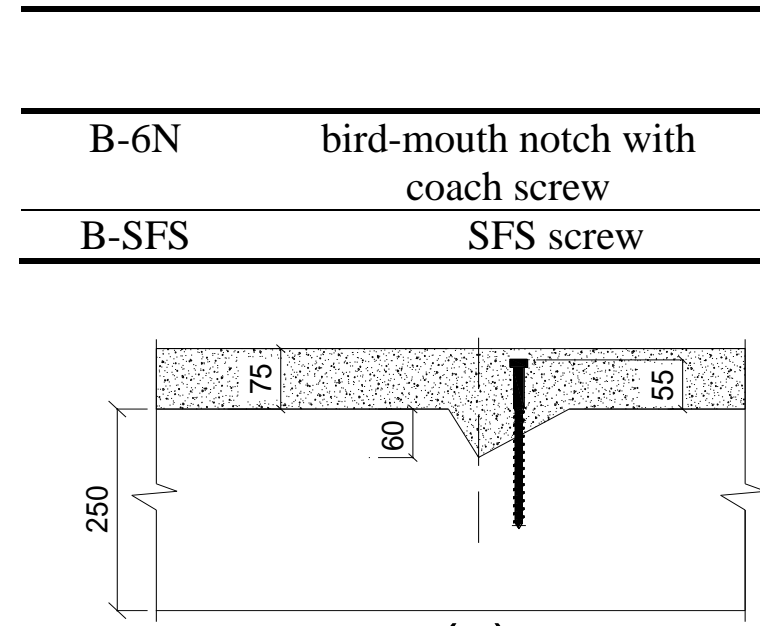

(a)
$\mathrm{K}_{\mathrm{sls}},(\mathrm{kN} / \mathrm{mm})$

36.9

54.9

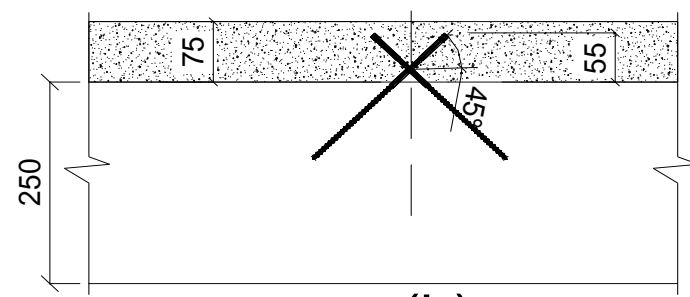

(b)

Figure 2. (a) Birds mouth with $\emptyset 16 \mathrm{~mm}$ coach screw and (b) SFS screw connections.

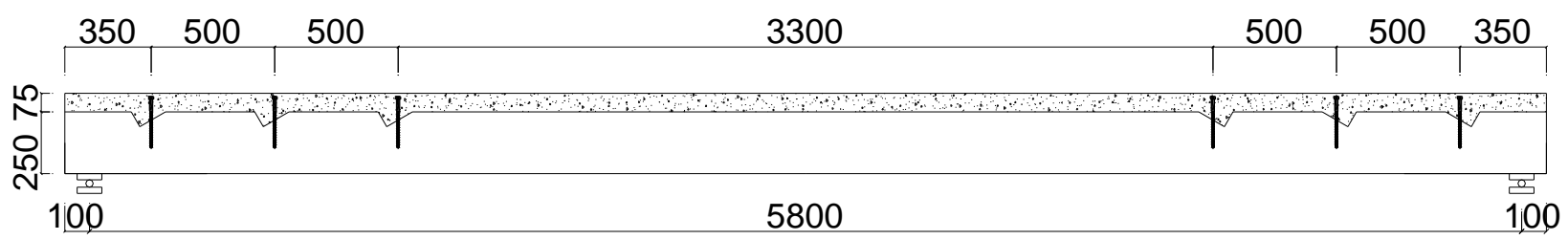

(a)

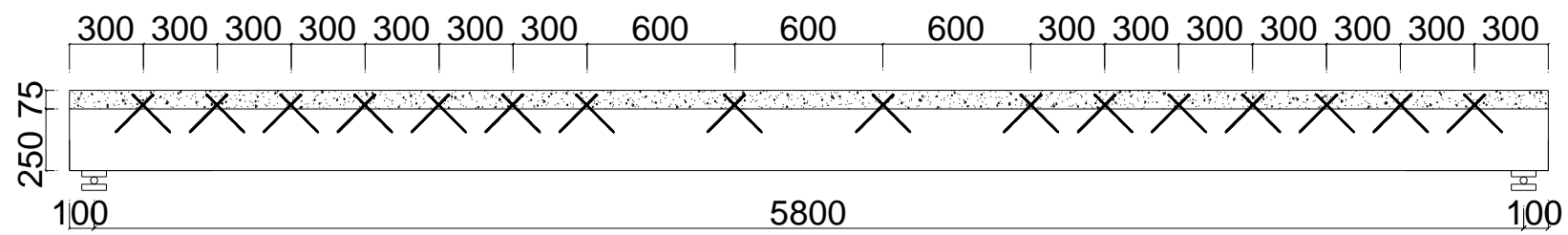

(b)

Figure 3. (a) Beam B-6N and (b) Beam B-SFS.

A short term static test was done to determine the bending stiffness of the composite beams before they were subjected to a long-term test conditions. The results are shown in Table 2, where "EI" refers to the tested effective stiffness of the composite beams.

Table 2. TCC beams bending stiffness.

\begin{tabular}{ccc} 
Specimen & $\begin{array}{c}\text { Stiffness, } \\
(\mathrm{kN} / \mathrm{m})\end{array}$ & $\begin{array}{c}\text { EI } \\
\left(10^{12} \mathrm{Nmm}^{2}\right)\end{array}$ \\
\hline
\end{tabular}




\begin{tabular}{ccc}
\hline B_6N & 1254 & 4.34 \\
\hline B_SFS & 1323 & 4.60 \\
\hline
\end{tabular}

\subsection{LONG-TERM TEST}

\subsubsection{TEST SET-UP AND INSTRUMENTATION}

Figure 4, shows the long-term test set up. The beams were loaded with equally spaced lead bars (Figure 5) which were arranged such that the bars apply a uniformly distributed load of $1.05 \mathrm{kN} / \mathrm{m}(1.7 \mathrm{kPa})$. The load level is such that no plasticity in any material is expected to occur immediately after the loads have been applied. A ratio of up to $20 \%$ of the failure load including the self-weight is what could be expected to be present on timber concrete composite floors under normal use. The air humidity was artificially accentuated using a humidifier positioned to apply uniform water vapour to the fog-room. The fog-room is made air-tight to avoid loss of humidity during the wet conditions.

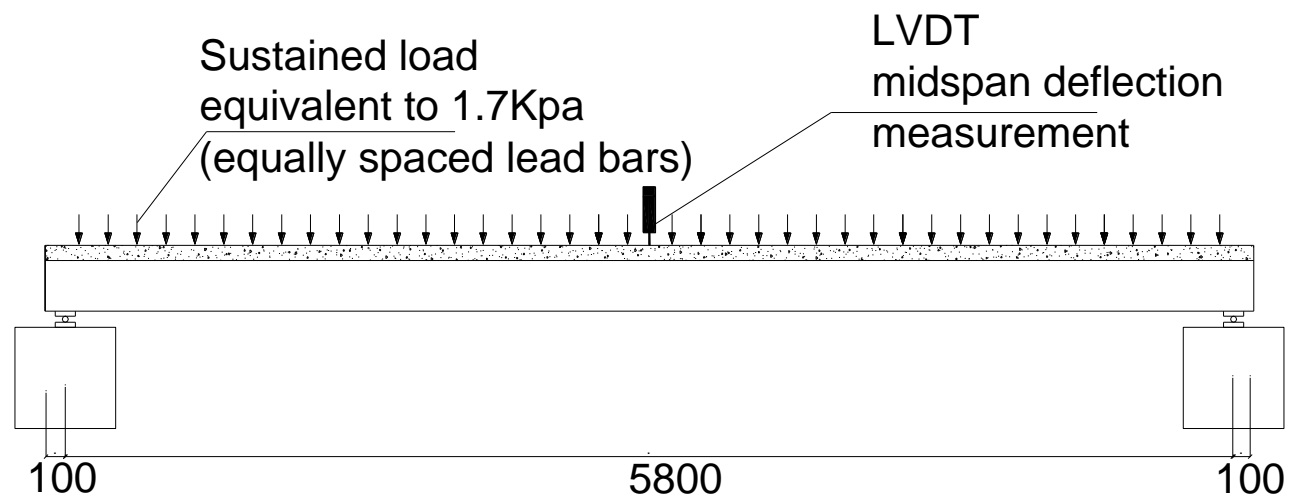

Figure 4. Test set up (measured in $\mathbf{m m}$ ).

The quantities that have been monitored are mid-span deflection using LVDTs (Linear Voltage Displacement Transducers) with a range $\pm 25 \mathrm{~mm}$, relative humidity and temperature of the room using climate loggers and moisture content of the timber using small timber blocks placed beneath the TCC beams. 


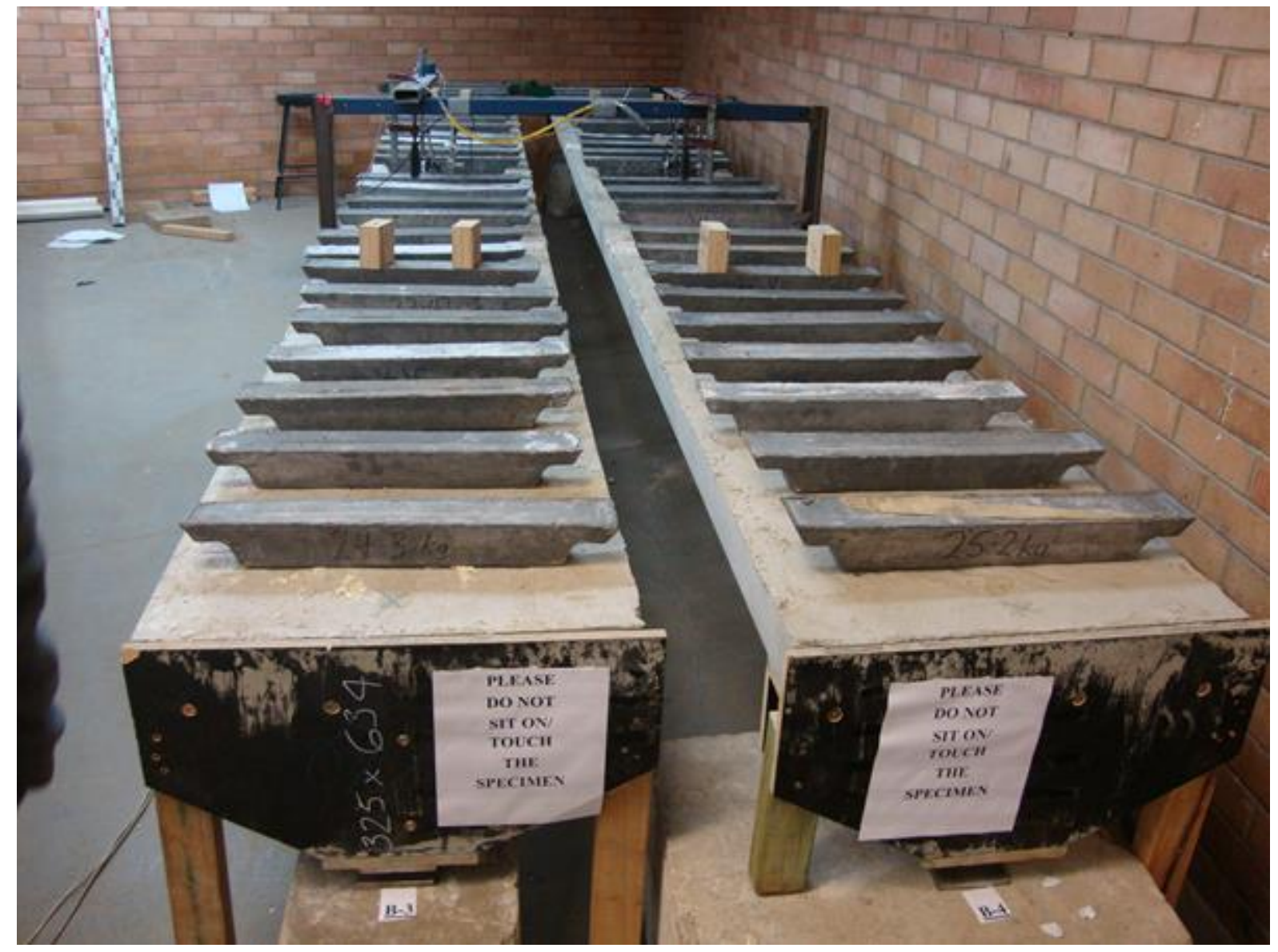

Figure 5. Beams under quasi-permanent loads (lead bars).

The instantaneous elastic mid-span deflections immediately after the application of the loads are shown in Table 3.

Table 3. Instantaneous elastic mid-span deflection.

\begin{tabular}{lll}
\hline Specimen & $\begin{array}{l}\text { Instantaneous elastic deflection } \\
(\mathrm{mm})\end{array}$ \\
\hline B-6N & 4.39 & \\
\hline B-SFS & 4.17 & \\
\hline
\end{tabular}

\subsubsection{ENVIRONMENTAL CONDITIONS}

The relative humidity $(\mathrm{RH})$ and temperature of the room are measured regularly every hour. The changes in $\mathrm{RH}$, moisture content and temperature are shown in Figure 6, for the last two and half years. The test is on-going. 


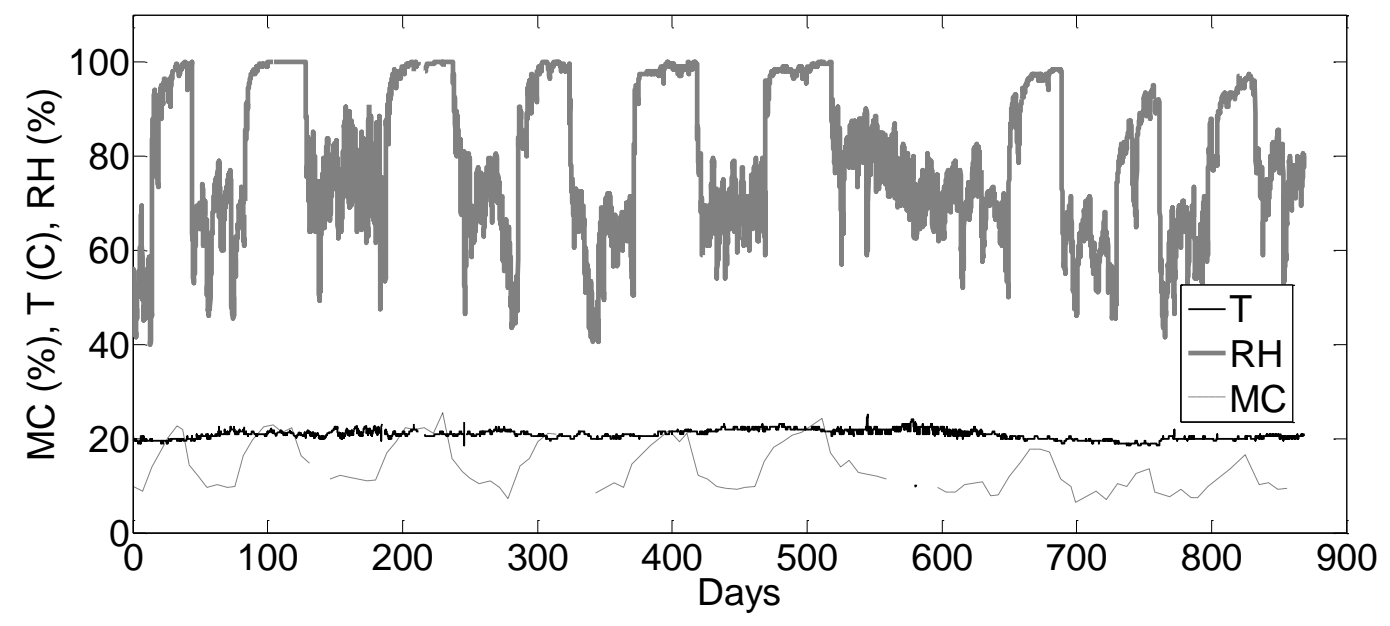

Figure 6. Changes in relative humidity, moisture content and temperature.

This environmental condition, based on Euro code 5, can be assigned to service class 3 ; it is characterized by moisture content in the material corresponding to a temperature of $20^{\circ} \mathrm{c}$ and relative humidity of the surrounding air exceeding $85 \%$.

\subsubsection{MOISTURE CONTENT}

To monitor the variation of moisture content in LVL joists, separate moisture content samples with 100x100x45 mm sizes cut from same batch of LVL were kept beneath the TCC beams and the changes in the level of moisture are measured regularly every week. The test samples for the moisture content are shown in Figure 7.

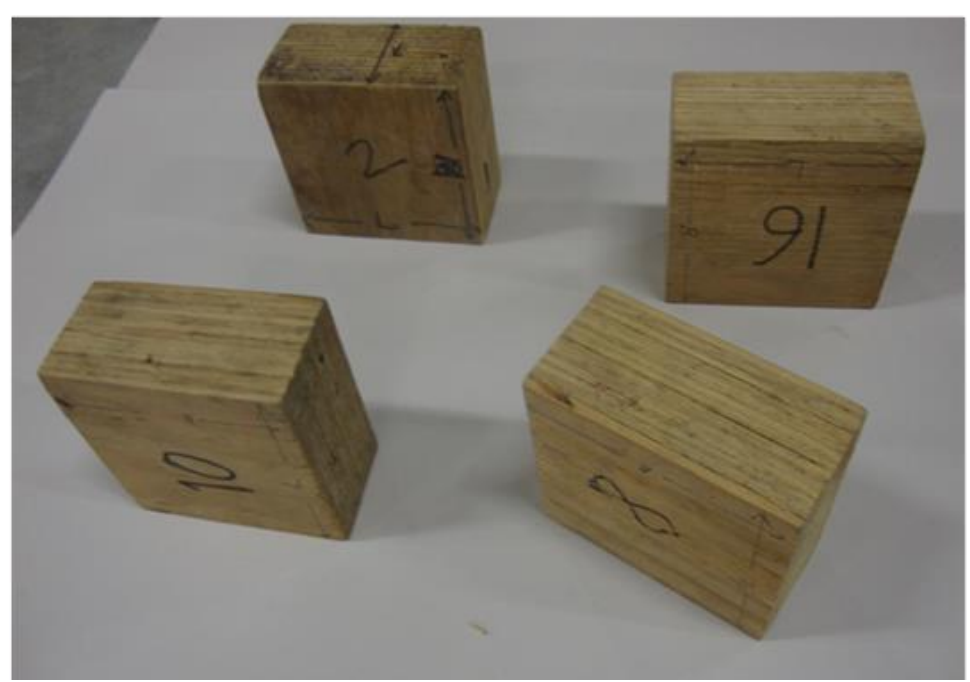

Figure 7. LVL MC Test samples. 
The oven-dry method as described in AS/NZ 1080.1:1997 is used in moisture content measurement and the moisture content obtained from the test samples was around 9 $\%$ at the start of the test and increased to above $20 \%$ after the humidifier was operated. It is observed from the result that it takes at least two weeks for the moisture content samples to attain $10 \%$ moisture content increment.

\subsubsection{LONG-TERM DEFLECTION}

The mid-span deflection was measured every minute during loading of the specimen for the initial 24 hours and every hour for the remaining of the long-term test. Figure 8, shows the mid-span deflection, moisture content versus time of the TCC beams.

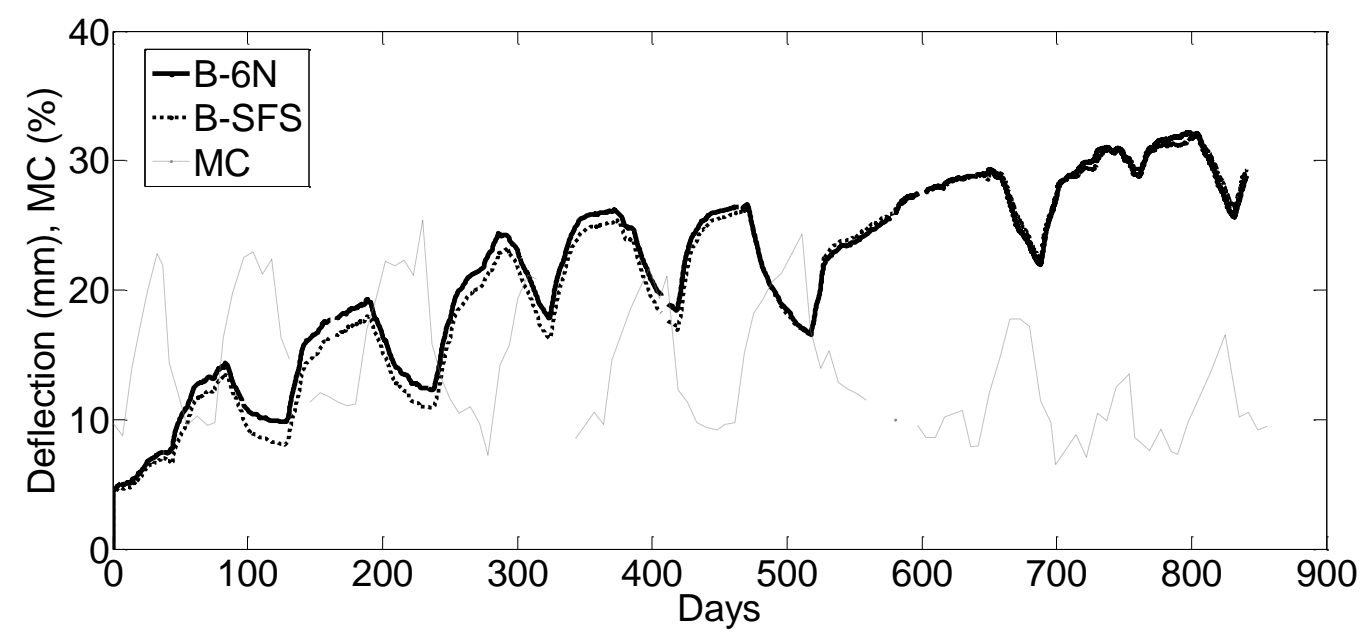

Figure 8. Mid-span deflection, moisture content versus time.

The specimens were loaded when the humidity chamber was at normal room environmental conditions which will be referred as dry state here onwards. Despite the instantaneous elastic deflection due to the applied loads very little additional deflection due to creep occurred. After, approximately one week water vapour was admitted, and the deflection increased in both the beams (Figure 8), this period referred as wet period is the first absorption period in the test, and the beams responded with increase in their deflections. In this wet period the air humidifier was used to increase and maintain the air humidity approximately at $100 \%$, this was then followed by dry period. The humidity chamber was opened and an air fun was used to increase the ventilation. During this period (desorption) the deflection in both the beams increased sharply with the deflection reaching more than twice their instantaneous defections. When the humidity chamber kept at this state the rate of defection increase slows down tending to reach some limiting values.

The beams were then again exposed to the wet period by admitting water vapour to the chamber, the defection in the beams suddenly changes direction and started to 
recover and the recovery continues as the air humidity was maintained at high $\mathrm{RH}$ levels. This procedure was repeated every four to six week except in some instances the duration may be longer due to instrument malfunction or other reasons. The length of the humidity cycle is four to six weeks and is monitored using the moisture content measurements on the moisture content samples

The results of the long-term investigation indicates that the long-term deflection of the TCC beams is accelerated due to the variation in air humidity in the humidity chamber and most of the change in deflection occurs within period during which moisture content cycle changes, and is more pronounced during a period when the humidity changes from wet to dry (Figure 9). The moisture content of the beams under load, cycled from dry to wet and back to dry again; the deformation also followed a cyclic pattern i.e. the beam deflections fluctuated in response to the cyclic air humidity of the chamber. However the recovery in each cycle is only partial and the total amount of creep is very large as shown in Figure 9. It should be noted that creep increased during drying and decreased during the wetting cycle with the exception of the initial wetting when creep increased.

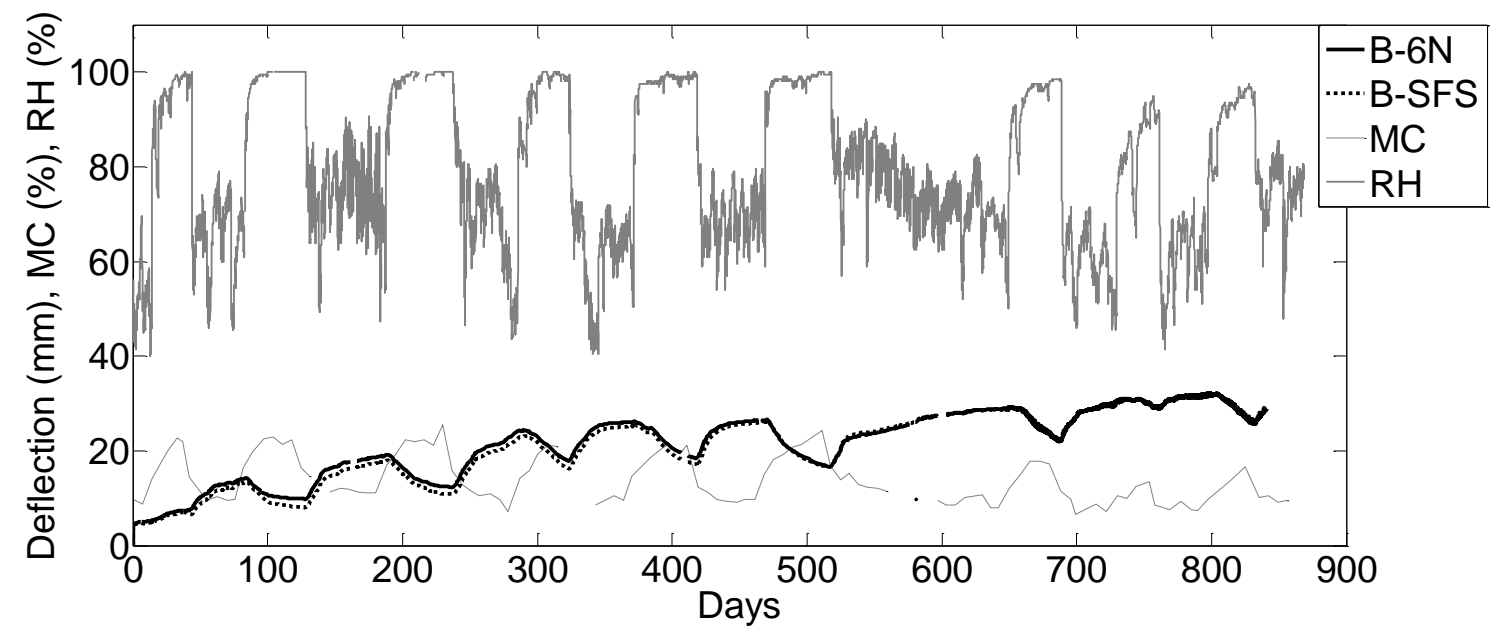

Figure 9. A comprehensive plot of deflection, RH\% and MC \%.

Three distinct behaviours were observed in the long-term test of these beams;

- increase in RH \& MC followed by an increase in deflection in the first one week (first adsorption)

- decrease in $\mathrm{RH}$ and $\mathrm{MC}$ followed by an increase in deflection in all dry periods (desorption)

- increase in RH and MC followed by decrease in deflection (local recovery) in all wet periods (adsorptions) 
The significant MC variation may have contributed to the high creep and deflection. The findings from this test show that it is not just the level of the moisture content that affects creep deflections. The rate of change, number and length of the cycles have a pronounced effect on the deflections, with rapid changes in moisture content (air humidity) producing more sever creep under bending loads also reported in Yeoh (2013). The rapid response to the change in MC is pronounced when the humid cycle changes from wet to dry, during this transition the moisture leaves the surfaces at faster rate than from the middle cross section of the LVL, causing a faster reaction from the beams. During the dry period the defection increased faster initially and then followed by a very slow rate when the environment is maintained in the dry conditions and showing tendency to flatten at some point. However, this is not the case when the humidity changes from dry to wet.

The following observation has been reported by several researchers (Capretti \& Cecotti, 1996, Kenel \& Meierhofe 1998, Lukaswezkas, 2009 and Yeoh 2009); When TCC beam is exposed to naturally varying environmental conditions in bending, an increase in the ambient relative humidity of the air causes an increase in timber moisture content, which promotes elongation of the timber beam, but this is prevented by the concrete slab. The overall effect is, therefore, a downward deflection, and self-equilibrated stress distribution over the composite cross-section. However, it needs to be emphasised that in semi-controlled environmental conditions characterized by moisture cycling; except the first cycle in all other cycles, increase in air humidity causes an increase in timber moisture content, which causes recovery of deflection while in the contrary a decrease in air humidity causes loss of moisture from the timber, which causes a rapid increase in the deflection of the TCC beams. Although there are hardly available literatures on the long-term experimental investigations on TCC beams subjected to cyclic humidity conditions in bending, this behaviour has been reported as typical creep behaviour of wood in bending (Armstrong 1960, Gibson 1996, Hearmon 1964, and Toratti 1993). Toratti (1993) explained the oscillation of the creep curves ( the alternate increase of deflection and recovery of deflection) is the shrinkage strain of wood, since the shrinkage is of much higher in magnitude perpendicular to the cell wall, this would result in higher shrinkage values when wood is compressed and less when tensioned as compared to unstressed state. Based on this explanation it can be argued that the effect of drying shrinkage of concrete is not significant enough to reverse the situation.

The creep mechanism is worst for long span structural composite beams where the stiffness of the floors is much more dependent on the composite action between the concrete and the timber joists. It was confirmed by several authors that the long-term behaviour of TCC is significantly influenced by the variation of the MC, concrete creep and the various interaction of shrinkage and creep, shrinkage and swelling of the LVL, and creep of the connection system, contributes a significant additional deflection in TCC floor structures. 
Both the beams (B-6N and B-SFS) have attained most of the deflection with in one and half years, as was also found out by several researches that most of the deflection developed during the first one and half to two years, after which the deflection tends to either plateaus or to increase much more slowly (Cecotti et al. 2006, Yeoh 2013). However, the deflection from these beams is showing a distinct increase throughout the period, with minimal reduction in the rate of deflection increase to the end of this reporting period. Similar finding was also reported in Kenel et al. (1998).

The changes in temperature also are found to significantly affect the long-term deflection of the TCC beams. Generally a reduction in temperature causes a shortening of both the concrete slab and, to a lesser extent, the timber beam. The overall effect is then a downs ward deflection (Lukaswezka 2009). Yeoh (2013) also reported a low temperature and high $\mathrm{RH}$, increased the MC of the LVL and consequently caused the deflection to increase whilst higher temperatures and low $\mathrm{MC}$, reduced the deflection. In this investigation the temperature of the humidity chamber remained quasi-constant $\left(20 \pm 2{ }^{\circ} \mathrm{C}\right)$ with little or no variation in temperature throughout the test period. Hence, the influence of the temperature is either none or negligible to be observed in this test.

\section{CONCLUSIONS}

This paper reports the results of an experimental test performed on two $5.8 \mathrm{~m}$ clear span TCC beams with two different type of connection. The beams were under a sustained load in sheltered indoor conditions and subjected to cyclic humidity condition. The most important quantities such as mid-span deflection, moisture content, relative humidity and temperature of the environment were continuously monitored through-out the test.

The conclusions made are (i) the relative humidity monitored during the long-term test varied from $45 \%$ to $100 \%$ while the timber moisture content fluctuated in the range of $7 \%$ to $20 \%$ and temperature remained quasi constant $\left(21{ }^{\circ} \mathrm{C} \pm 1\right)$, (ii) cycling the humidity has accelerated the creep response of the beams and induced very high deflection about seven times their initial deflection, (iii) the mid-span deflection markedly augmented with in two years of the long-term test, with a final value well above the limits usually adopted by national regulations.

\section{ACKNOWLEDGEMENT}

This experimental research work has been carried out by means of the financial supports of Structural Timber Innovation Company (STIC). Which is gratefully acknowledged.

\section{REFERENCES}

Ahmadi, B. H. and Saka, M. P. (1993). 'Behaviour of composite TCC floor' Journal of Structural Engineering, vol. 119, no. 11, pp. 3111-30 
Armstrong, L. D. and Kingston, R. S. T. (1960). ' Effect of moisture changes on creep in wood' Nature, 185 (4716), 862-863.

Armstrong, L. D. and Christensen, G. N. (1961). ' Influence of moisture changes on deformation of wood under stress' Nature, 191 (4791), 869-870.

Armstrong, L. D. and Grossman, P. U. A. (1972). 'The behaviour of Particle board and hard board beams during Moisture cycling', Wood Science and Technology, vol. 6, p. 9.

Brebbia, C. A., Dominguez, J., Escrig, F. (1991). 'Structural Repair and Maintenance of Historical Buildings II' Vol.1 General Studies, Materials and Analysis ,Proceedings of the Second International Conference, held in Seville,Spain,14-16 May.

Bou Said, E., Jullien, J. F. and Ceccotti, A. (2004). 'Long term modelling of timberconcrete composite structures in variable climates', paper presented to the 8th WCTE, Lahti, Finland, June 2004.

Ceccotti, A., Fragiacomo, M. and Giordano, S. (2006). 'Long-term and collapse tests on a timber concrete composite beam with glued in connection', Materials and Structures, 2006, p. 10.

Epmeier, H., Johonsson, M., Kliger, R. and Westin, M. (2007). "Bending creep performance of modified timber, Holz Roh- Werkst.

Fragiacomo, M. (2006). 'Long-term behaviour of timber-concrete composite beams. I: finite element modelling and validation', Struc Eng, vol. 132(1), pp. 13-22.

Fragiacomo, M., Amadio, C. and Macorini L. (2007). 'Short- and Long-term performance of the "Tecnaria" stud connector for timber-concrete composite beams', Materials and Structures RILEM 40(10), vol. 40, no. 10, p. 13.

Fragiacomo, M. and Ceccotti, A. (2004). 'A simplified Approach for Long-Term Evaluation of Timber-Concrete Composite Beams', 8th WCTE, vol. 2, Lahti, Finland, pp. 537-42.

Gibson, E. J. (1965). 'Creep of wood: Role of water and effect of a changing moisture content', Nature, no. 4980.

Gowda, C., Kortesmaa, M., Ranta-Maunus, A. (1996). 'Long term creep tests on timber beams in heated and non-heated environment', Espoo, vol. VTT Publications 278, p. 35.

Grantham, R., Fragiacomo, M., Nogarol, C., Zidaric, I. and Amadio, C. (2004). 'Potential upgrade of timber frame buildings in the UK using timber-concrete composites', In 8th World Conference on Timber Engineering WCTE, 2: 5964.

Hailu, M., Gerber, C., Shrestha, R., Crews, K. (2012).'Long-term behaviour of Timber-Concrete-Composite beams', in '12th WCTE', Proceedings of the World Conference on Timber Engineering, New Zealand, Auckland.

Hearmon, R. P., J. (1964). 'Moisture content changes and creep of wood', Forest products, p. 2.

Kenel, A. \& Meierhofer, U. (1998). Long-term performance of timber-concrete composite structural elements, Report.No. 115/39, EMPA, Dübendorf, Switzerland, in German.

Khorsandnia, N., Hamid, R., Crews, K. (2012). ' Experimental and analytical investigation of short-term behaviour of LVL-concrete composite 
connections and beams', Journal of Construction and Building Materials, 37(2012) 229-238.

Lukaszewska, E., Fragiacomo, M. \& Johnsson, H. (2010). 'Laboratory Tests and Numerical Analyses of Prefabricated Timber-Concrete Composite Floors', Journal of Structural Engineering, vol. 136, no. 1, pp. 46-55.

Meierhofer, A. U. (1993). 'Tests on Timber Concrete Composite structural elements 'International council for building research studies and documentation, working commission W18 - Timber Structures, CIB-W18/ 2-7-5.

Toratti, T. (1993). 'Long term deflection of timber beams', Rakenteiden Mekaniikka, vol. 26 No 3 1993, pp. 19-28.

Yeoh, D. F., and Deam, B. (2010). 'Long-term behaviour of LVL-concrete composite connection and beams under sustained loads', unpublished, University of Canterbury. 